\title{
Peach Fruit Weight Is Influenced by Crop Density and Fruiting Shoot Length but not Position on the Shoot
}

\author{
Richard P. Marini ${ }^{1}$ and Donald L. Sowers ${ }^{2}$ \\ Department of Horticulture, Virginia Polytechnic Institute and State University, Blacksburg, \\ VA 24061-0327
}

\begin{abstract}
Additional index words. Prunus persica, leaf : fruit ratio, crop density
Abstract. The relationship between peach [Prunus persica (L.) Batsch] fruit position and fruit weight (FW) was studied in experiments involving thinned vs. nonthinned fruiting shoots, shoots with and without axillary shoots, and trees with varying crop densities (CDs). FW was not consistently related to position on the shoot, and the influence of fruit position varied depending on the presence of axillary shoots on the fruiting shoot. FW was best related to fruiting shoot length and total shoot length per fruit (1-year-old plus current-season wood). Mean FW was also influenced by the number of fruit per shoot $\times$ CD interaction, a result indicating that $\mathrm{FW}$ depends on photosynthate from leaves in the immediate vicinity of the fruit as well as photosynthate from more distant parts of the tree.
\end{abstract}

Removing excess fruit to improve fruit size and quality is an important practice in commercial peach orchards. Fruit size was positively related to leaf area per fruit on girdled branches (Jones, 1932; Overholser and Claypool, 1931; Weinberger, 1931; Weinberger and Cullinan, 1932) and negatively related to fruit per tree (Johnson and Handley, 1989). Final fruit size was negatively related to the physiological age of the fruit at the time of thinning (Havis, 1962). Although total fruit number and weight per tree is typically reduced by fruit thinning, high returns for large fruit usually improve orchard profitability.

Blake (1925) observed that peaches developing near the terminals of fruiting shoots were larger than fruit at the shoot base. Spencer and Couvillon (1975) confirmed those observations and also reported that flower buds at the terminal nodes bloomed earlier than buds at basal positions. Corelli-Grappadelli and Coston (1991) reported a similar pattern of bloom development and noted that fruit were smallest at the distal end of fruiting shoots. These conflicting results may be partly related to the physiological age of fruit at harvest, because Spencer and Couvillon (1975) harvested all fruit on the same calendar date, whereas, Corelli-Grappadelli and Coston (1991) used multiple harvests so that all fruit were harvested at the same stage of maturity. Other factors that may have contributed to the conflicting results, but are not discussed, include cultivar, tree vigor, crop density (CD), and thinning date.

In addition to position of fruit on the shoot, fruit size was affected by shoot length, fruit distribution on the shoot, and number of fruit per centimeter of shoot length (Corelli-Grappadelli and Coston, 1991). These authors hypothesized that differences in fruit size resulted from altered carbohydrate partitioning between plant parts. Actively growing shoots may be strong sinks for carbohydrates, and young fruit developing near the shoot apex may be at more of a competitive disadvantage than fruit farther from the apex (Corelli-Grappadelli and Coston, 1991). Since translocation in peach can occur over relatively long distances and among different branches (Chalmers et al., 1975; Marini et al., 1991), the magnitude of fruit size enhancement resulting from

Received for publication 18 May 1992. Accepted for publication 25 June 1993. The cost of publishing this paper was defrayed in part by the payment of page charges. Under postal regulations, this paper therefore must be hereby marked advertisement solely to indicate this fact.

${ }^{1}$ Associate professor.

${ }^{2}$ Research technician. thinning individual shoots may be influenced by the leaf : fruit ratio on individual shoots and by the tree's CD.

Experiments relating fruit size to factors such as shoot length, fruit position on a shoot, leaf area per shoot, fruit per shoot, and CD on a whole tree may help clarify the poorly understood mechanism of carbohydrate partitioning in peach trees and will provide information for modifying pruning and thinning practices. The purpose of this study was to evaluate the individual and interrelated effects of fruit position on a shoot, shoot length, and $\mathrm{CD}$ of whole trees on peach fruit weight $(\mathrm{FW})$.

\section{Materials and Methods}

'Redhaven' fruit position and axillary shoots, 1987. Six 4-yearold 'Redhaven' trees were used to study the influence of fruit position and the presence of axillary shoots on FW. At 40 days after full bloom (DAFB) three fruiting shoots with axillary shoots and three fruiting shoots with only terminal shoots per tree were thinned to three fruit per shoot. All shoots were $\approx 45 \mathrm{~cm}$ long and were thinned to one fruit at the distal, middle, and basal positions. The largest fruit at each position was retained during thinning. All nontreatment shoots were thinned to $\approx 20 \mathrm{~cm}$ between fruit. On 3 Aug., when the ground color for all fruit on treatment shoots was yellowish-green, all fruit were harvested and weighed. The experiment was a randomized complete-block design with trees serving as blocks, and treatments were arranged as a factorial of two shoot types and three fruit positions. Data were analyzed by analysis of variance (ANOVA) using SAS's General Linear Models procedure (Barr et al., 1985). Since the shoot type $\times$ fruit position interaction was significant $(P=0.05)$, data were reanalyzed by shoot type.

'Redhaven' shoot length and number of fruit per shoot, 1988. Four 5-year-old 'Redhaven' trees were used to study the interaction of shoot length and number of fruit per shoot on FW. At 45 DAFB, 24 fruiting shoots per tree were selected around the tree periphery at $1.6 \mathrm{~m}$ above the ground. A factorial treatment structure consisting of three shoot lengths $(15,30$, and $60 \mathrm{~cm})$ and four fruit loads (one, two, three, and four fruit per shoot) provided 12 treatment combinations. Fruit were equally spaced along the shoot. Each combination was replicated twice per tree. The rest of each tree was thinned to a spacing of $\approx 20 \mathrm{~cm}$ between fruit. On 7 or 10 Aug., when the ground color was yellowish-green, each fruit was 
weighed, and lengths and leaf numbers were recorded for the 1987 wood, the 1988 terminal shoot, and all axillary shoots developing from buds on the 1987 wood.

The experiment was a randomized complete-block design with trees serving as blocks. Data were analyzed by ANOVA to test equality of shoot lengths and fruit loads. Multiple regression models were developed using the maximum $R^{2}$ improvement technique with the stepwise procedure and SAS's REG procedure. Mean FW per shoot was the response variable, and the regressor variables included the linear and quadratic components of 1988 shoot length, 1987 shoot length, terminal shoot length, total (1987 +1988 wood) shoot length, total shoot length per fruit, total leaf number per shoot, and leaves per fruit.

'Redhaven' CD, shoot length, and fruit load, 1991. Twelve 8year-old 'Redhaven' trees were used to study the interaction of $\mathrm{CD}$, shoot length, and number of fruit per shoot on FW. At 43 DAFB, four secondary scaffold limbs per tree were selected. All fruiting shoots per secondary scaffold limb were hand thinned to either one, two, three, or four fruit per shoot. The largest fruit on each shoot was retained during thinning. There were seven to 10 fruiting shoots per secondary scaffold limb and shoot lengths ranged from 10 to $60 \mathrm{~cm}$. The remaining shoots on each tree were then hand thinned to provide CDs ranging from 1.8 to 11.3 fruit/ $\mathrm{cm}^{2}$ trunk cross-sectional area (TCSA).

Since fruit maturity was influenced by $\mathrm{CD}$ and number of fruit per shoot, each shoot was harvested when most fruit on that shoot had yellowish-green ground color. Each shoot, with the fruit, was detached from the tree, each fruit was weighed, and the lengths of 1990 wood and 1991 wood were recorded. Multiple regression models were developed using the maximum $R^{2}$ improvement technique with SAS's stepwise procedure. Total FW per shoot and mean FW per shoot were the response variables, and the regressor variables included linear and quadratic components of $\mathrm{CD}$, number of fruit per shoot, 1990 shoot length, 1991 shoot length, and total $(1990+1991)$ shoot length.

'Cresthaven' fruiting pattern and CD, 1991. Twelve 4-yearold 'Cresthaven' trees were used to study the interaction of CD and fruiting pattern on FW. At 48 DAFB, four shoots, 40 to $50 \mathrm{~cm}$ long, per tree were selected. Two shoots were thinned to three fruit, with one fruit at the distal, middle, and basal positions. The largest fruit at each position was retained during thinning. The remaining two shoots were not thinned and had 15 to 25 fruit per shoot. The largest fruit at the distal, middle, and basal sections of each shoot was tagged. The remaining shoots on each of four trees were thinned to provide a light, moderate, or heavy CD. Mean CD was 9.9, 15.3, and 26.9 fruit $/ \mathrm{cm}^{2}$ TCSA, respectively, for light, moderate, and heavy CDs. When about one-half of the fruit on a tree developed yellowish-green ground color, all fruit on that tree were harvested and counted. Fruit from the three positions of the experimental shoots were weighed. Regression models were developed for each fruit position per shoot-thinning treatment (six models), where FW was the response variable and linear and quadratic components of CD were regressor variables. In all cases, FW was linearly related to $\mathrm{CD}$. Homogeneity of slopes and intercepts for the linear models was tested with SAS's REG procedure using combinations of shoot-thinning treatments and fruit position as dummy variables. Fifteen pair-wise comparisons were performed.

\section{Results}

When thinned to three fruit uniformly distributed along the shoot in 1987, 'Redhaven' FW was influenced by the interaction of fruit position and the presence of axillary shoots (Table 1). FW was greatest at the middle section of shoots with axillary shoots and the basal section of shoots with no axillary shoots. Since these results indicated a localized influence of leaf : fruit ratio on $\mathrm{FW}$, an experiment was performed in 1988 to determine the relationship between number of leaves per shoot and FW on individual fruiting shoots.

When 'Redhaven' shoots, varying in length from 15 to $60 \mathrm{~cm}$, were thinned in 1988 to one to four fruit per shoot, mean FW was independent of fruit position (data not shown). The interactions involving shoot length, fruit position, and number of fruit per shoot were not significant $(P=0.05)$. FW and yield per shoot were poorly related $\left(R^{2} \leq 0.09\right)$ to the length of the 1 -year-old shoot (1987 growth), but were better related to the length of axillary shoots per 1 -year-old shoot $\left(R^{2} \geq 0.18\right)$, terminal shoot length $\left(R^{2}\right.$ $\geq 0.26$ ), and total current-season shoot length per 1-year-old shoot $\left(R^{2} \geq 0.20\right)$ (Table 2$)$. FW was linearly related to leaves per shoot $\left(R^{2}=0.21\right)$ and leaves per fruit $\left(R^{2}=0.27\right)$, but yield per shoot was not related to leaves per fruit (Table 2). FW was not related to number of fruit per shoot (data not shown). FW was generally better related to all regressor variables than yield per shoot.

Terminal shoot length, axillary shoot length, and total currentseason shoot length increased nonlinearly with increasing fruiting shoot (1987 wood) length (Table 3). Leaves per shoot and leaves per fruit increased linearly with increasing fruiting shoot length $\left(R^{2}\right.$ $=0.61$ and 0.39 , respectively). Leaves per shoot also increased quadratically with increasing total current-season shoot length $\left(R^{2}\right.$ $=0.83$ ) (Table 3).

Since the 1988 results indicated a relationship between length of fruiting shoot and FW on that shoot, an experiment was performed in 1991 to study the effects of shoot length and number of fruit per shoot on FW on trees with varying CDs. This experiment was performed to study the relative importance of carbohydrates produced near the fruit and carbohydrates transported from other parts of the tree.

When shoots of varying lengths on 'Redhaven' trees thinned to varying CDs were thinned to one to four fruit per shoot in 1991, FW was affected significantly $(P=0.05)$ by $\mathrm{CD}$, number of fruit per shoot, and the $\mathrm{CD} \times$ number of fruit per shoot interaction. $\mathrm{A}$ multiple regression model developed from the complete data set indicated that mean FW per shoot was influenced by total shoot length $(1990+1991$ wood $)$ and the linear $\times$ linear and quadratic $\times$ quadratic interaction components of $\mathrm{CD} \times$ number of fruit per shoot: mean $\mathrm{FW}=138.8+0.09 \mathrm{SL}-4.4(\mathrm{CD} \times \mathrm{FN})+0.06\left(\mathrm{CD}^{2}\right.$ $\times \mathrm{FN}^{2}$ ), model $R^{2}=0.61, P<0.001, \mathrm{n}=186$, where $\mathrm{SL}=$ shoot length and $\mathrm{FN}=$ number of fruit per shoot. Because regression models with three regressor variables are difficult to interpret, a response surface was developed for $\mathrm{FW}$, thus pooling number of fruit per shoot, using shoot length and CD as the independent variables (Fig. 1). FW increased quadratically with increasing shoot length and declined linearly with increasing CD.

Table 1. 'Redhaven' fruit weight ( $\mathrm{g}$ ) as influenced by fruit position and the presence of axillary shoots developing on fruiting shoots (1-year-old growth) in $1987 . \mathrm{z}$

\begin{tabular}{lllc}
\hline \hline Fruit & \multicolumn{2}{c}{ Axillary shoots } & \\
\cline { 2 - 3 } position & No & Yes & Mean \\
\hline Distal & $88 \mathrm{~b}$ & $116 \mathrm{ab}$ & 102 \\
Middle & $87 \mathrm{~b}$ & $121 \mathrm{a}$ & 104 \\
Basal & $98 \mathrm{a}$ & $107 \mathrm{~b}$ & 104 \\
Mean & 91 & 115 & \\
\hline
\end{tabular}

${ }^{\mathrm{z}}$ Since fruit position interacted with shoot type $(P=0.05)$, means were separated within columns by Tukey's HSD, $P=0.05, \mathrm{n}=6$. 
Table 2. 'Redhaven' fruit weight (FW) (g) and yield per shoot (g) as influenced by different measures of shoot length in $1988^{\mathrm{z}}$.

\begin{tabular}{llc}
\hline \hline Regressor variable & \multicolumn{1}{c}{ Regression equation } & Model $R^{2}$ \\
\hline 1987 Shoot length $(\mathrm{cm})$ & FW $=110.0+0.006 \mathrm{x}^{2}$ & $0.09^{* * *}$ \\
& Yield $=234.9+0.0003 \mathrm{x}^{2}$ & $0.07^{*}$ \\
1988 Axillary shoot length/shoot $(\mathrm{cm})$ & FW $=106.3+0.28 \mathrm{x}-0.000003 \mathrm{x}^{2}$ & $0.32^{* * *}$ \\
& Yield $=239.2+0.05 \mathrm{x}$ & $0.18^{* * *}$ \\
Terminal shoot length/shoot $(\mathrm{cm})$ & FW $=90.5+0.16 \mathrm{x}-0.00008 \mathrm{x}^{2}$ & $0.37^{* * *}$ \\
& Yield $=185.7+0.38 \mathrm{x}$ & $0.26^{* * *}$ \\
Total 1988 shoot length/shoot $(\mathrm{cm})$ & FW $=102.1+0.03 \mathrm{x}-0.000003 \mathrm{x}^{2}$ & $0.36^{* * *}$ \\
& Yield $=230.3+0.05 \mathrm{x}$ & $0.20^{* * *}$ \\
Total 1988 shoot length/fruit $(\mathrm{cm} /$ fruit) & FW $=102.6+0.05 \mathrm{x}-0.000008 \mathrm{x}^{2}$ & $0.41^{* *}$ \\
& Yield $=112.7+24.7 \mathrm{x}^{2}$ & $0.78^{* *}$ \\
Leaves/shoot & FW $=105.0+0.14 \mathrm{x}$ & $0.21^{* * *}$ \\
& Yield $=219.2+0.52 \mathrm{x}$ & $0.14^{* * *}$ \\
No. leaves/fruit & FW $=106.1+0.24 \mathrm{x}$ & $0.27^{* * *}$ \\
& Yield $=$ & $\mathrm{NS}$ \\
\hline
\end{tabular}

${ }^{\mathrm{z}}$ All intercepts and regression coefficients are significant $(P<0.05, \mathrm{n}=91)$.

Ns,******** Nonsignificant or significant at $P=0.05,0.01$, or 0.001 , respectively.

Table 3. Relationships between different indexes of shoot length and leaves per shoot for 'Redhaven' trees in 1988. ${ }^{\mathrm{z}}$

\begin{tabular}{llr}
\hline \hline Regressor variable & \multicolumn{1}{c}{ Regression equation } & Model $R^{2}$ \\
\hline 1987 Shoot length $(\mathrm{cm})$ & Term. shoot length $(\mathrm{cm})=121.0+0.0007 \mathrm{x}^{2}$ & $0.31^{* * * *}$ \\
& Axillary shoot length $(\mathrm{cm})=-78.5+0.003 \mathrm{x}^{2}$ & $0.38^{* * * *}$ \\
& Total 1988 shoot length $(\mathrm{cm})=42.4+0.005 \mathrm{x}^{2}$ & $0.39^{* * * *}$ \\
& Leaves/shoot $=-38.2+0.42 \mathrm{x}$ & $0.61^{* * * *}$ \\
& Leaves/fruit $=17.8+0.22 \mathrm{x}$ & $0.39^{* * * *}$ \\
& Total 1988 shoot length/fruit $(\mathrm{cm} /$ fruit $)=38.3+0.003 \mathrm{x}^{2}$ & $0.33^{* * * *}$ \\
Total 1988 shoot length/shoot $(\mathrm{cm})$ & Leaves/shoot $=31.7+0.10 \mathrm{x}-0.000005 \mathrm{x}^{2}$ & $0.83^{* * * *}$ \\
\hline
\end{tabular}

${ }^{\mathrm{z}}$ All intercepts and regression coefficients are significant $(P<0.05, \mathrm{n}=91)$.

${ }^{* * *}$ Significant at $P=0.01$.

When 'Cresthaven' trees were thinned to varying CDs and individual shoots were not thinned or thinned to three fruit, the main effect of shoot position did not significantly influence FW (data not shown). However, there was a significant $(P<0.05)$ three-way interaction of fruit position $\times$ shoot thinning $\times \mathrm{CD}$. To evaluate this interaction, individual regression models were developed for all six combinations of shoot thinning and fruit position; FW was the response variable and $C D$ was the regressor variable. For all combinations of shoot thinning and fruit position, FW declined linearly with increasing CD, but the intercept and slope for fruit at the distal position of nonthinned shoots were significantly less $(P$ $=0.05$ ) than for the other five combinations of shoot thinning and fruit position (Fig. 2).

\section{Discussion}

FW was not consistently influenced by fruit position. In 1987, 'Redhaven' FW was greatest at the basal position of shoots with no axillary shoots and lowest at the basal position of shoots with axillary shoots (Table 1). The relationship between FW and CD for distal fruit on nonthinned shoots of 'Cresthaven' trees in 1991 differed from all other combinations of fruit position and shootthinning treatments (Fig. 2). Although not recorded, we observed more axillary shoots on thinned than nonthinned shoots.

Our data may help explain previous conflicting reports. Spencer and Couvillon (1975) found fruit at distal nodes to be $\approx 5 \%$ larger than fruit at basal nodes. Corelli-Grappadelli and Coston (1991) reported smallest fruit with lowest soluble solids content at the distal positions and suggested that the terminal shoot may be a stronger competitor for photosynthate than young fruit at the distal end of the shoot. Our data indicate that the above hypothesis may be true when the terminal shoot is the only source of photosynthate on a fruiting shoot. When lateral shoots, which are additional sources of photosynthate, develop on a fruiting shoot, the sourcesink relations within the fruiting shoot may change so that fruit at distal positions are more competitive for photosynthate. Our data also indicate that FW may be affected by the shoot position $x$ number of fruit per shoot $\times$ CD interaction ('Cresthaven' 1991). Compared to fruit at the basal shoot position, 'Cresthaven' FW at the distal position was smaller on trees with low CDs and larger on trees with high CDs, and differences were greatest on nonthinned shoots (data not presented). Unfortunately, CD and the presence of axillary shoots on the fruiting shoots were not reported in previous studies. Corelli-Grappadelli and Coston (1991) studied the relationship between fruiting pattern and peach FW for two seasons in South Carolina and reported that buds at the distal end of the shoot bloomed earlier than basal buds, but fruit diameter was not largest at the distal end. Since anthesis progresses from the distal nodes toward the basal nodes, on a given calendar date, distal fruit may be larger than basal fruit due to differences in DAFB. During the later stages of the final swell, peach fruit may increase in diameter $1.5 \mathrm{~mm} /$ day (Blake et al., 1931). Thus, the $5 \%$ difference in fruit diameter from the distal nodes to the basal nodes reported by Spencer and Couvillon (1975) may have been an artifact of harvest date, and results may have differed had all fruit been harvested at the same DAFB or with similar ground color, as was the case in our study and in the study of Corelli-Grappadelli and Coston (1991). The effect of fruit position on peach fruit size 


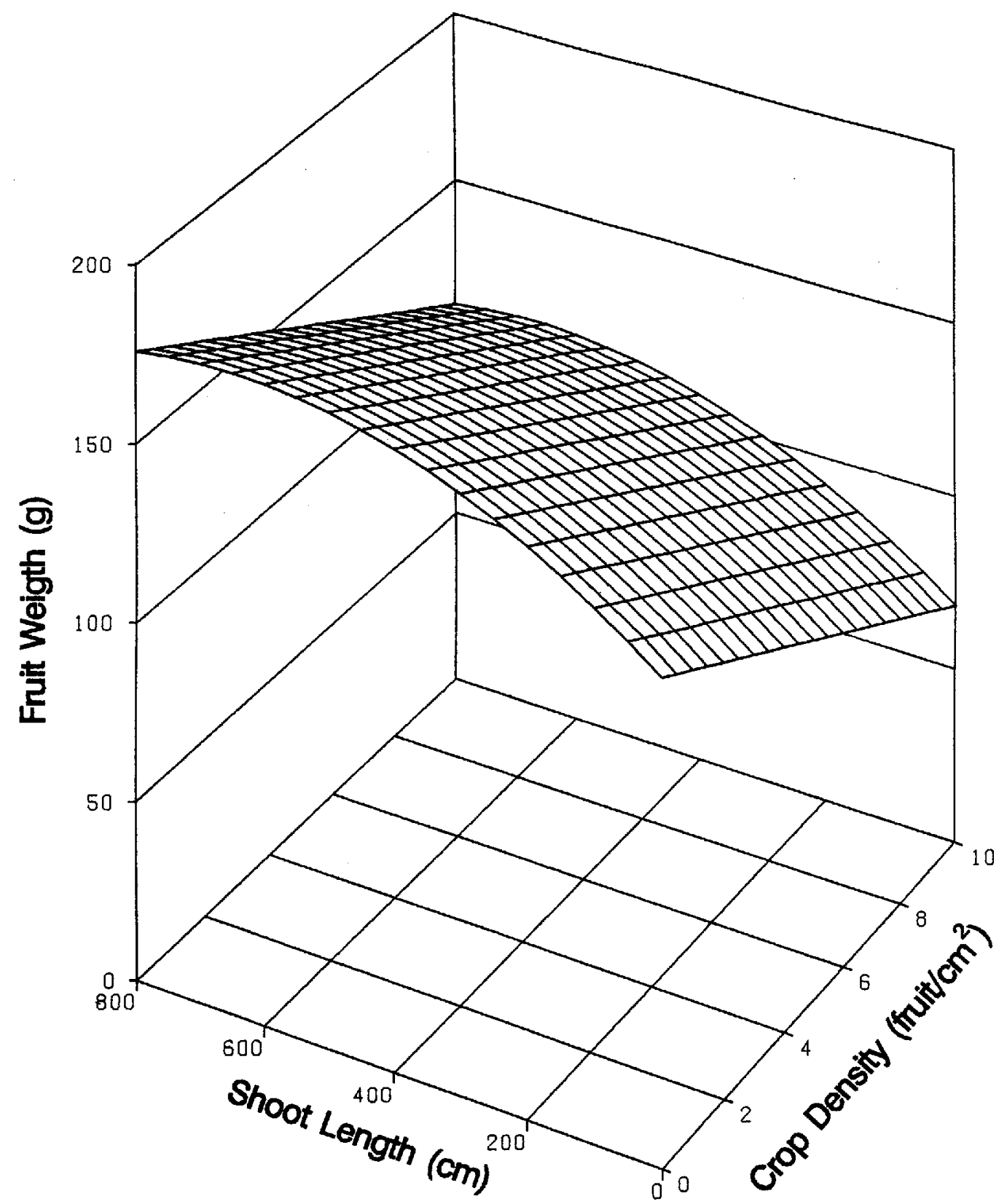

Fig. 1. Predicted mean fruit weight (FW) per shoot of 'Redhaven' peaches in 1991 as influenced by crop density (CD) and total fruiting shoot length (SL) (1990 wood plus 1991 wood). $\mathrm{FW}=131.6+0.14 \mathrm{SL}-0.0001\left(\mathrm{SL}^{2}\right)-6.32 \mathrm{CD}, R^{2}=0.50, P=0.0001, \mathrm{n}=186$.

is too inconsistent to warrant changes in thinning practices.

When number of fruit per shoot was held constant, our data and those of Corelli-Grappadelli and Coston (1991) indicated a positive relationship between length of fruiting shoot and mean FW. This relationship likely was related to the leaf : fruit ratios in the immediate vicinity of the fruit because number of leaves per shoot was linearly related to fruiting shoot length $\left(R^{2}=0.83\right)$ (Table 3$)$. In other studies using girdled limbs, peach fruit size was positively related to leaf : fruit ratio (Overholser and Claypool, 1931; Weinberger, 1931) and negatively related to number of fruit per tree (Johnson and Handley, 1989). In 1988, 'Redhaven' FW was positively related to total current-season shoot length (Table $2)$. Stepwise regression indicated that FW was better related to total current-season shoot length per fruit $\left(R^{2}=0.36\right)$ than leaves per fruit $\left(R^{2}=0.27\right)$ or total leaves per shoot $\left(R^{2}=0.21\right)$. The number of axillary shoots, current-season shoot length per fruit, current-season shoot length, and terminal shoot length increased quadratically with increasing 1-year-old shoot length (1987 wood). Thus, the presence of axillary shoots on the fruiting shoot likely is important for maximum $\mathrm{FW}$, and axillary shoot length was positively related to 1 -year-old shoot length $\left(R^{2}=0.38\right)$ (Table $2)$. Since the length of current-season shoots developing on the 1year-old fruiting shoot is important for maximum FW, an area deserving further study is investigating methods of inducing more axillary shoot growth per fruiting shoot. Bloom thinning, pruning with heading cuts, or applying plant growth regulators would be potential treatments.

Results from this study also provide some insight concerning carbohydrate partitioning within peach trees. Results from the 1991 'Redhaven' experiment support the data of Johnson and Hanley (1989), where mean FW was negatively related to number of fruit per tree. 


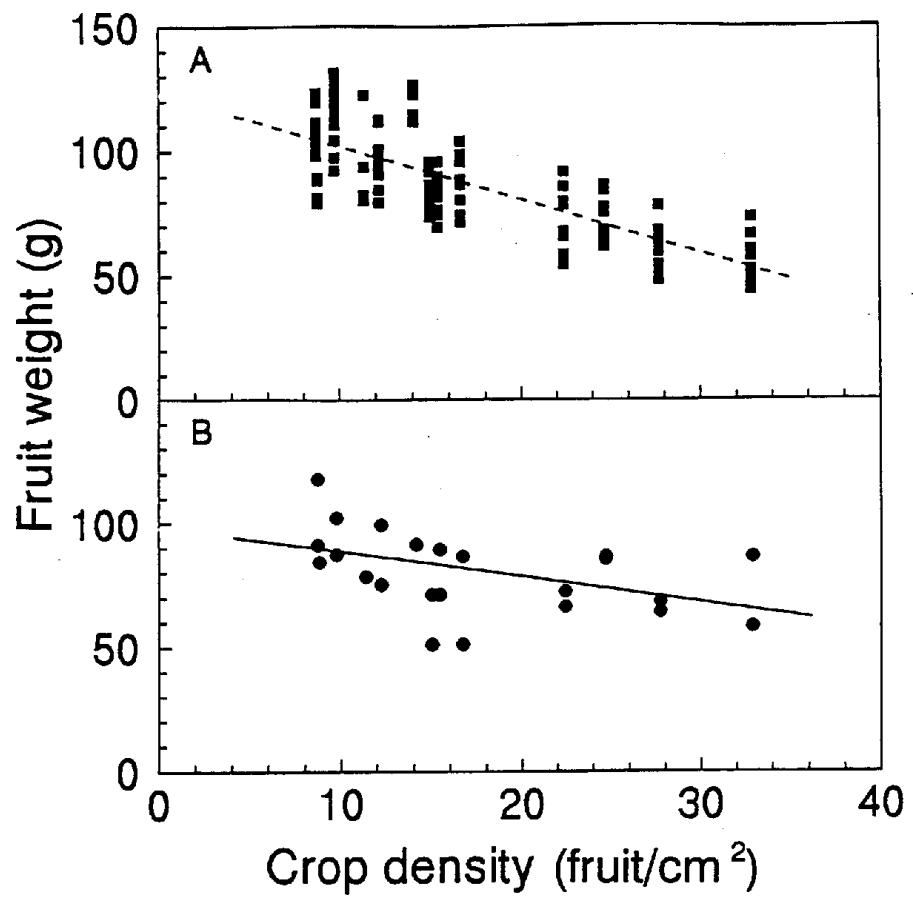

Fig. 2. 'Cresthaven' fruit weight (FW) in 1991 as influenced by the interaction of fruit position and thinning individual shoots on trees with varying crop densities (CDs). FW data were pooled for the basal and middle positions on thinned and nonthinned shoots and the distal position of thinned shoots. (A) FW $=122.8-2.14$ $\mathrm{CD}, R^{2}=0.54, P=0.0001, \mathrm{n}=240$. For fruit at the distal position of nonthinned shoots $(\mathbf{B}), \mathrm{FW}=98.6-1.02 \mathrm{CD}, R^{2}=0.28, P=0.001, \mathrm{n}=48$.

Stepwise regression for the model presented in Fig. 1 indicates that $\mathrm{CD}$ explained $35 \%$ of the variation in $\mathrm{FW}$; length of an individual fruiting shoot explained $14 \%$. Therefore, FW likely depends primarily on the photosynthate pool of the entire tree and to a lesser extent on the photosynthate from leaves in the immediate vicinity. Results from the 1991 'Cresthaven' experiment, where the relationship between mean FW and CD differed for thinned and nonthinned shoots, support this concept. For nonthinned shoots, $\mathrm{FW}=135.2-4.46 \mathrm{CD}+0.07(\mathrm{CD})^{2}, R^{2}=0.51, P$ $<0.001, \mathrm{n}=75$; for thinned shoots, $\mathrm{FW}=126.0-2.14 \mathrm{CD}, R^{2}=$ $0.63, P<0.001, \mathrm{n}=75$. Fruit dependence on distant sources of photosynthate was also demonstrated in girdling studies where peach (Chalmers and Van den Ende, 1975) and sweet cherry
(Roper et al., 1987) FW was greatest for fruit on the side of the girdle containing leaves. Marini et al. (1991) found that shading limbs negatively influenced peach FW more when limbs were girdled. Therefore, if peaches are thinned nonuniformly throughout the canopy, the lack of thinning individual shoots will be partially compensated by adequately thinning most of the tree.

\section{Literature Cited}

Barr, A.J., J.H. Goodnight, J.P. Sall, and J.T. Helwig. 1985. SAS user's guide: Statistics. version 5. SAS Institute, Cary, N.C.

Blake, M.A. 1925. The growth of the fruit of the Elberta peach from blossom bud to maturity. Proc. Amer. Soc. Hort. Sci. 22:29-39.

Blake, M.A., O.W. Davidson, R.M. Addoms, and G.T. Nightingale. 1931.

Development and ripening of peaches as correlated with physical characteristics, chemical composition, and histological structure of the fruit flesh: I. Physical measurements of growth and flesh texture in relation to the market and edible qualities of the fruit. N.J. Expt. Sta. Bul. 525.

Chalmers, D.J. and B. van den Ende. 1975. A reappraisal of the growth and development of peach fruit. Austral. J. Plant Physiol. 2:623-634.

Corelli-Grappadelli, L. and D.C. Coston. 1991. Thinning pattern and light environment in peach tree canopies influence fruit quality. HortScience 26:1464-1466.

Havis, A.L. 1962. Effects of time of fruit thinning of Redhaven peach. Proc. Amer. Soc. Hort. Sci. 80:172-176.

Johnson, R.S. and D.F. Handley. 1989. Thinning response of early midand late-season peaches. J. Amer. Soc. Hort. Sci. 114:852-855.

Jones, I.D. 1932. Further observations on influence of leaf area on fruit growth and quality in the peach. Proc. Amer. Soc. Hort. Sci. 29:34-38.

Marini, R.P., D. Sowers, and M.C. Marini. 1991. Peach fruit quality is affected by shade during final swell of fruit growth. J. Amer. Soc. Hort. Sci. 116:383-389.

Overholser, E.L. and L.L. Claypool. 1931. The relation of leaf area per peach to physical properties and chemical composition. Proc. Amer. Soc. Hort. Sci. 28:15-17.

Roper, T.R., W.H. Loescher, J. Keller, and C.R. Rom. 1987. Sources of photosynthate for fruit growth in 'Bing' sweet cherry. J. Amer. Soc. Hort. Sci. 112:808-812.

Spencer, S. and G.A. Couvillon. 1975. The relationship of node position to bloom date, fruit size, and endosperm development of the peach, Prunus persica (L.) Batsch cv. Sullivan's Elberta. J. Amer. Soc. Hort. Sci. 100:242-244.

Weinberger, J.H. 1931. The relation of leaf area to size and quality of peaches. Proc. Amer. Soc. Hort. Sci. 28:18-22.

Weinberger, J.H. and F.P. Cullinan. 1932. Further studies on the relation between leaf area and size of fruit, chemical composition, and fruit bud formation in Elberta peach. Proc. Amer. Soc. Hort. Sci. 29:23-27. 